\title{
Prevalence of $\beta$-Lactam Drug-Resistance Genes in Escherichia coli Contaminating Ready-to-Eat Lettuce
}

\author{
Ningbo Liao, ${ }^{1-3}$ Clarissa A. Borges, ${ }^{1}$ Julia Rubin, ${ }^{1}$ Yuan $\mathrm{Hu},{ }^{4}$ Hector A. Ramirez, ${ }^{1}$ \\ Jiang Chen, ${ }^{2}$ Biao Zhou, ${ }^{2}$ Yanjun Zhang, ${ }^{2}$ Ronghua Zhang, ${ }^{2}$ Jianmin Jiang, $^{2}$ and Lee W. Riley ${ }^{1}$
}

\begin{abstract}
Thirty-four Escherichia coli isolates from 91 ready-to-eat lettuce packages, obtained from local supermarkets in Northern California, were genotyped by multilocus sequence typing, tested for susceptibility to antimicrobial agents, and screened for $\beta$-lactamase genes. We found 15 distinct sequence types (STs). Six of these genotypes (ST1198, ST2625, ST2432, ST2819, ST4600, and ST5143) have been reported as pathogens found in human samples. Twenty-six (76\%) E. coli isolates were resistant to ampicillin, 17 (50\%) to ampicillin/sulbactam, $8(23 \%)$ to cefoxitin, and $7(20 \%)$ to cefuroxime. $b a_{\mathrm{CTX}-\mathrm{M}}$ was the most prevalent $\beta$-lactamase gene, identified in eight (23\%) isolates. We identified a class A broad-spectrum $\beta$-lactamase SED-1 gene, $b l a_{\mathrm{SED}}$, reported by others in Citrobacter sedlakii isolated from bile of a patient. This study found that fresh lettuce carries $\beta$-lactam drug-resistant $E$. coli, which might serve as a reservoir for drug-resistance genes that could potentially be transmitted to pathogens that cause human infections.
\end{abstract}

Keywords: antimicrobial resistance, $\beta$-lactamase genes, Escherichia coli, ready-to-eat lettuce

\section{Introduction}

$\mathbf{T}$ HE INCREASE AND spread of antimicrobial drug-resistant bacterial strains has become a problem worldwide, and food may contribute as an important source of antibiotic resistance genes (ARGs) found in the human intestine. In particular, fresh vegetables carry saprophytic bacteria that harbor drug-resistance genes, which can enter the human gut when it is eaten uncooked (Raphael et al., 2011; Berman and Riley, 2013; Richter et al., 2019). Escherichia coli have been regarded as an indicator of contamination and health risk in foods (Paruch and Mæhlum, 2012). Some groups of E. coli can cause gastrointestinal infections as well as extraintestinal infections. In the United States, multistate outbreaks of gastroenteric illness caused by lettuce contaminated with $E$. coli $\mathrm{O} 157: \mathrm{H} 7$ have been widely reported (Glowacki et al., 2019). More recent studies have shown sequence types (STs) of extraintestinal pathogenic E. coli (ExPEC) shared by E. coli isolates from retail meat products and patients with community-acquired urinary tract infections (Yamaji et al., 2018; Borges et al., 2019).

In this study, we wished to discover if ExPEC and drugresistant strains of ExPEC can be found on green leafy veg- etables. Therefore, the purpose of this study was to determine the STs and ARG carriage of E. coli isolated from packaged ready-to-eat lettuce.

\section{Materials and Methods}

Ninety-one ready-to-eat lettuce packages were purchased from chain supermarkets located within a 11 kilometers vicinity of a university community in Northern California from October 2018 to July 2019. These lettuce products represented 12 brands and the main types included Boston (butterhead lettuce), iceberg (crisphead lettuce), and green/red leaf lettuce, which were distributed by four different California producers.

For each package, $25 \mathrm{~g}$ of lettuce were placed in a UVpretreated polyethylene bag containing $50 \mathrm{~mL}$ of sterile phosphate-buffered saline (PBS; pH 7.4). After brief kneading by hand, the lettuce was incubated in PBS for $45 \mathrm{~min}$ at room temperature and washed three times. The combined rinsate $(50 \mathrm{~mL} \times 3)$ was then centrifuged at $12,000 \mathrm{~g}$ for $5 \mathrm{~min}$ at room temperature. The pellet was resuspended in $2 \mathrm{~mL}$ of PBS and preincubated in double strength MacConkey broth (Difco) at a $1: 1$ dilution at $35^{\circ} \mathrm{C}$ for $24 \mathrm{~h}$. A separate $10 \mu \mathrm{L}$

\footnotetext{
Divisions of ${ }^{1}$ Infectious Diseases and Vaccinology and ${ }^{4}$ Epidemiology, School of Public Health, University of California, Berkeley, California, USA.

${ }^{2}$ Department of Nutrition and Food Safety, Zhejiang Provincial Center for Disease Control and Prevention, Hangzhou, China.

${ }^{3}$ College of Food Science and Engineering, Jiangxi Agricultural University, Nanchang, China.

This manuscript has been posted on bioRxiv since October 30, 2019, and has since been updated to indicate its publication in Foodborne Pathogens and Disease.
} 
aliquot was then spread-plated on MacConkey agar (Difco) to isolate Gram-negative bacteria. E. coli was presumptively identified by lactose fermentation and indole (Sigma-Aldrich) tests.

Single colonies from tryptic soy agar plates were selected and inoculated into $2 \mathrm{~mL}$ tryptic soy broth and incubated in a shaking incubator for $15 \mathrm{~h}$ at $37^{\circ} \mathrm{C}$. The aliquots of grown cultures were used to isolate DNA as described previously (Yamaji et al., 2018). The allelic number and the corresponding genotype number were designated by the curator of the multilocus sequence typing (MLST) based on the sevengene scheme described at website https://enterobase.warwick .ac.uk/species/ecoli/allele_st_search

All isolates were assessed for susceptibility to ampicillin (AMP), cefoxitin (FOX), cefotaxime (CTX), cefuroxime (CXM), ceftriaxone (CRO), ampicillin/sulbactam (SAM), ceftazidime (CAZ), fosfomycin (FOS), gentamicin (CN), nitrofurantoin (NIT), trimethoprim-sulfamethoxazole (TMP-
SMX), and nalidixic acid (NAL) by the standard disk diffusion assay, according to the Clinical and Laboratory Standards Institute-CLSI (CLSI, 2015). E. coli ATCC 25922 was used as reference strain in all tests.

The E. coli isolates were tested for the presence of $b l a_{\mathrm{TEM}}$, $b l a_{\mathrm{SHV}}, b l a_{\mathrm{CTX}-\mathrm{M}}$, and $b l a_{\mathrm{OXA}} \beta$-lactamase genes by polymerase chain reaction (Dallenne et al., 2010). DNA sequences were visually inspected, aligned, and compared against sequences in GenBank with BLAST (https://blast.ncbi.nlm .nih.gov/Blast.cgi).

Statistical analysis was performed by Fisher's exact test (two-tailed) with significance set at $p \leq 0.05$.

\section{Results and Discussion}

Of the 91 lettuce packages, $47(52 \%)$ contained organic and $44(48 \%)$ contained conventionally grown (nonorganic) lettuce. Thirty-four E. coli isolates were recovered from 18

Table 1. Sequence Types, Antimicrobial Resistance Profiles, and $\beta$-Lactamase (bla) Genes OF THE 34 ESCHERICHIA COLI ISOLATED FROM READY-TO-EAT LETTUCE ${ }^{\mathrm{a}}$

\begin{tabular}{|c|c|c|c|}
\hline Strain $^{\mathrm{b}}$ & $S T$ & Antimicrobial resistance profile & $\beta$-lactamase gene ${ }^{\mathrm{c}}$ \\
\hline \multicolumn{4}{|c|}{ Organic lettuce } \\
\hline 1 & 8951 & $\mathrm{AMP}+$ & Other \\
\hline $2 \mathrm{~A}$ & UNK & $\mathrm{AMP}+\mathrm{SAM}+\mathrm{NA}+$ & Other \\
\hline $2 \mathrm{~B}$ & 8951 & Pan-susceptible ${ }^{\mathrm{d}}$ & None \\
\hline 3 & 2625 & $\mathrm{AMP}+$ & Other \\
\hline 4 & 5154 & AMP+FOS+ & Other \\
\hline $5 \mathrm{~A}$ & 8951 & $\mathrm{AMP}+\mathrm{SAM}+$ & $b l a_{\text {SHV }}$ type \\
\hline $5 B$ & UNK & $\mathrm{AMP}+\mathrm{SAM}+$ & Other \\
\hline $5 \mathrm{C}$ & 9285 & $\mathrm{AMP}+\mathrm{SAM}+$ & $b l a_{\text {TEM }}$ type \\
\hline 6 & 5154 & $\mathrm{AMP}+\mathrm{FOX}+\mathrm{CXM}+\mathrm{SAM}+$ & $b l a_{\mathrm{TEM}}$ type $+b l a_{\mathrm{SHV}}$ type \\
\hline 7A & UNK & $\mathrm{AMP}+\mathrm{SAM}+$ & $b l a_{\mathrm{TEM}}$ type $+b l a_{\mathrm{SHV}}$ type \\
\hline $7 \mathrm{~B}$ & UNK & $\mathrm{AMP}+\mathrm{SAM}+$ & Other \\
\hline 8 & 6374 & Pan-susceptible & None \\
\hline 9 & 4600 & $\mathrm{AMP}+\mathrm{FOX}+\mathrm{CXM}+$ & $b_{\text {CTX-м }}$ type \\
\hline 10 & 8951 & $\mathrm{AMP}+\mathrm{SAM}+$ & Other \\
\hline 11 & UNK & $\mathrm{AMP}+\mathrm{FOX}+\mathrm{CXM}+\mathrm{SAM}+$ & $b l a_{\mathrm{CTX}-\mathrm{M}}$ type \\
\hline $12 \mathrm{~A}$ & 6374 & $\mathrm{AMP}+$ & Other \\
\hline $12 \mathrm{~B}$ & 3222 & $\mathrm{AMP}+\mathrm{CXM}+\mathrm{SAM}+$ & Other \\
\hline $13 \mathrm{~A}$ & 1198 & $\mathrm{AMP}+\mathrm{SAM}+$ & Other \\
\hline 13B & 2432 & $\mathrm{AMP}+\mathrm{FOX}+\mathrm{CXM}+\mathrm{SAM}+$ & $b l a_{\mathrm{SHV}}$ type \\
\hline $14 \mathrm{~A}$ & UNK & $\mathrm{AMP}+\mathrm{SAM}+$ & Other \\
\hline 14B & 4277 & $\mathrm{AMP}+\mathrm{SAM}+$ & $b l a_{\mathrm{TEM}}$ type $+b l a_{\mathrm{SHV}}$ type \\
\hline $15 \mathrm{~A}$ & 2819 & $\mathrm{AMP}+\mathrm{CXM}+$ & $b_{\text {CTX-M }}$ type \\
\hline $15 \mathrm{~B}$ & 2819 & $\mathrm{AMP}+\mathrm{CXM}+$ & $b_{\text {CTX-M }}$ type \\
\hline 16 & 2432 & $\mathrm{AMP}+\mathrm{FOX}+$ & $b l a_{\mathrm{SHV}}$ type $+b l a_{\mathrm{CTX}-\mathrm{M}}$ type \\
\hline 17 & UNK & $\mathrm{AMP}+\mathrm{FOX}+$ & $b l a_{\mathrm{CTX}-\mathrm{M}}$ type \\
\hline 18 & UNK & $\mathrm{AMP}+\mathrm{SAM}+$ & $b l a_{\mathrm{TEM}}$ type \\
\hline \multicolumn{4}{|c|}{ Nonorganic lettuce } \\
\hline 19 & 5351 & Pan-susceptible & None \\
\hline 20 & 3567 & Pan-susceptible & None \\
\hline 21 & 6376 & $\mathrm{AMP}+\mathrm{SAM}+$ & Other \\
\hline 22 & UNK & Pan-susceptible & None \\
\hline 23 & 8951 & Pan-susceptible & None \\
\hline $24 \mathrm{~A}$ & UNK & AMP+SAM+ & Other \\
\hline 24B & 5143 & $\mathrm{FOX}+$ & $b l a_{\mathrm{CTX}-\mathrm{M}}$ type \\
\hline 25 & 5143 & $\mathrm{FOX}+$ & $b l a_{\mathrm{CTX}-\mathrm{M}}$ type \\
\hline
\end{tabular}

${ }^{\mathrm{a}}$ Isolates with intermediate susceptibility were classified as nonsusceptible.

${ }^{\mathrm{b}}$ Different strains isolated from the same package have the same number followed by a different letter.

'Other: ampicillin-resistant isolates that did not have any $b l a_{\mathrm{TEM}}$-type, $b l a_{\mathrm{CTX}-\mathrm{M}}$ type, $b l a_{\mathrm{OXA}}$-type and $b l a_{\mathrm{SHV}}$-type.

${ }^{\mathrm{d}}$ Pan-susceptible is defined as susceptible to the 12 antibiotics tested this study.

AMP, ampicillin; CXM, cefuroxime; FOS, fosfomycin; FOX, cefoxitin; NAL, nalidixic acid; SAM, ampicillin/sulbactam; ST, sequence type; UNK, unknown. 
(38\%) organic and $7(16 \%)$ conventionally grown lettuce $(p=0.01)$. The isolates were classified into 15 distinct STs. Ten isolates could not be assigned to a known ST (Table 1). The most common genotypes were ST8951 (16\%) and ST5154 (12\%). ST8951 has been previously identified in deciduous forest soil and turkey, including ground meat as well as clinical samples (https://enterobase.warwick.ac.uk/ species/index/ecoli). The type of clinical sample is not described in the database. ST5154 has been reported from cattle, but not from any human infections (Ribeiro et al., 2016; https://enterobase.warwick.ac.uk/species/index/ecoli). Other genotypes, including ST1198, ST2625, ST2432, ST2819, ST4600, and ST5143, have been described as pathogens in human samples from Japan (Fukuoka), USA (Nashville and Tennessee), or Canada, China (Hangzhou and Shanghai), and Korea, as noted in the MLST database and previous studies (https://enterobase.warwick.ac.uk/species/ index/ecoli).

ST1198 has been implicated in urinary tract infection and is a member of clonal complex 131 (Lee et al., 2010), which is one of the pandemic lineages of ExPEC (Riley, 2014). Foster et al. (2015) reported ST4600 as an enteropathogenic E. coli strain, isolated from a patient with diarrhea. The clinical sources of the other genotypes are not described.

Among 34 E. coli isolates, $26(76 \%)$ were resistant to AMP, $17(50 \%)$ to SAM, $8(23 \%)$ to FOX, $7(20 \%)$ to CXM, $1(3 \%)$ to FOS, and $1(3 \%)$ to NAL. Of the $\beta$-lactamase genes examined, $b l a_{\text {CTX-M }}$ was the most prevalent, found in $8(23 \%)$ isolates, followed by $b l a_{\mathrm{SHV}}$, detected in $5(15 \%)$ isolates, and $b l a_{\mathrm{TEM}}$ detected in $4(12 \%)$ isolates. The high frequency of $E$. coli strains carrying bla $a_{\mathrm{CTX}-\mathrm{M}}$ is surprising, considering that the most common $\beta$-lactam genes found in clinical strains of $E$. coli is $b l a_{\mathrm{TEM}}$ and/or bla ${ }_{\mathrm{SHV}}$ (Yamaji et al., 2018; Borges et al., 2019; Tarlton et al., 2019). The high frequency of CTX-M $\beta$ lactamase genes in ready-to-eat lettuce poses a public health concern, since it is the most common extended-spectrum betalactamases (ESBL) expressed by clinical strains of E. coli, which is becoming increasingly prevalent in extraintestinal infections worldwide (Yamaji et al., 2018; Borges et al., 2019; Richter et al., 2019; Tarlton et al., 2019).

To our surprise, in one strain (ST3222), we found a class A broad-spectrum $\beta$-lactamase SED-1 gene, bla $a_{\mathrm{SED}}$, reported by others to have been found in Citrobacter sedlakii in the bile fluid of a patient (Petrella et al., 2001). It suggests that some of these $\beta$-lactamase genes are horizontally transferred among saprophytic Gram-negative bacteria found in the environment, and that commensal $E$. coli from mammalian intestine contaminating lettuce could acquire them. Such genes can then enter the human intestine through ingestion of contaminated food product eaten uncooked.

\section{Conclusions}

We found that retail packaged lettuce purchased in Norther California frequently contains $E$. coli strains belonging to recognized ExPEC group, and that many of them carry ESBL genes. The magnitude of lettuce contributing to the spread of ExPECs and resistance genes into the human intestine may be underestimated.

\section{Disclosure Statement}

No competing financial interests exist.

\section{Funding Information}

This study was funded by the National Natural Science Foundation of China (no. 31701715), the U.S. Centers for Disease Control and Prevention program to combat antibiotic resistance under BAA no. 200-2016-91939, the Zhejiang Province Public Welfare Technology Application Research Project (no. LGN20C200004), and the National Health Commission Foundation of the People's Republic of China (WKJ-ZJ-1917).

\section{References}

Berman HF, Riley LW. Identification of novel antimicrobial resistance genes from microbiota on retail spinach. BMC Microbiol 2013;13:272-277.

Borges CA, Tarlton NJ, Riley LW. Escherichia coli from commercial broiler and backyard chickens share sequence types, antimicrobial resistance profiles, and resistance genes with human extraintestinal pathogenic Escherichia coli. Foodborne Pathog Dis 2019;16:813-822.

Clinical and Laboratory Standards Institute [CLSI]. Performance Standards for Antimicrobial Susceptibility Testing; Twenty-Fifth Informational Supplement. M100-S125. Wayne, PA: CLSI, 2015.

Dallenne C, Da Costa A, Decre D, Favier C, Arlet G. Development of a set of multiplex PCR assays for the detection of genes encoding important beta-lactamases in Enterobacteriaceae. J Antimicrob Chemother 2010;65:490-495.

Foster MA, Iqbal J, Zhang C, McHenry R, Cleveland BE, Romero-Herazo Y, Gómez-Duarte OG. Enteropathogenic and enteroaggregative $E$. coli in stools of children with acute gastroenteritis in Davidson County, Tennessee. Diagn Microbiol Infect Dis 2015;83:319-324.

Glowacki EM, Glowacki JB, Chung AD, Wilcox GB. Reactions to foodborne Escherichia coli outbreaks: A text-mining analysis of the public's response. Am J Infect Control 2019;47: 1280-1282.

Lee MY, Choi HJ, Choi JY, Song M, Song Y, Kim SW, Chang HH, June SI, Kim YS, Ki HK, Son JS, Kwon KT, Heo ST, Yeom JS, Shin SY, Chung DR, Peck KR, Song JH, Ko KS. Dissemination of ST131 and ST393 communityonset, ciprofloxacin-resistant Escherichia coli clones causing urinary tract infections in Korea. J Infection 2010;60:146153.

Paruch AM, Mæhlum T. Specific features of Escherichia coli that distinguish it from coliform and thermotolerant coliform bacteria and define it as the most accurate indicator of faecal contamination in the environment. Ecol Indic 2012;23:140142.

Petrella S, Clermont D, Casin I, Jarlier V, Sougakoff W. Novel class A $\beta$-lactamase Sed-1 from Citrobacter sedlakii: Genetic diversity of $\beta$-lactamases within the Citrobacter genus. Antimicrob Agents Chemother 2001;45:2287-2298.

Raphael E, Wong LK, Riley LW. Extended-spectrum betalactamase gene sequences in Gram-negative saprophytes on retail organic and nonorganic spinach. Appl Environ Microbiol 2011;77:1601-1607.

Ribeiro TG, Novais Â, Peixe L, Machado E. Atypical epidemiology of CTX-M-15 among Enterobacteriaceae from a high diversity of non-clinical niches in Angola. J Antimicrob Chemoth 2016;71:1169-1173.

Richter L, Du Plessis EM, Duvenage S, Korsten L. Occurrence, identification, and antimicrobial resistance profiles of extendedspectrum and AmpC $\beta$-lactamase-producing enterobacteriaceae 
from fresh vegetables retailed in Gauteng province, South Africa. Foodborne Pathog Dis 2019;16:421-427.

Riley LW. Pandemic lineages of extraintestinal pathogenic Escherichia coli. Clin Microbiol Infec 2014;20:380-390.

Tarlton NJ, Moritz C, Adams-Sapper S, Riley L W. Genotypic analysis of uropathogenic Escherichia coli to understand factors that impact the prevalence of $\beta$-lactam-resistant urinary tract infections in a community. J Glob Antimicrob Resist 2019;19:173-180.

Yamaji R, Friedman CR, Rubin J, Suh J, Thys E, McDermott P, Hung-Fan M, Riley LW. A population-based surveillance study of shared genotypes of Escherichia coli isolates from retail meat and suspected cases of urinary tract infections. mSphere 2018;3:e0179-18.

Address correspondence to: Lee W. Riley, $M D$ Divisions of Infectious Diseases and Vaccinology School of Public Health University of California Berkeley, CA 94720

USA

E-mail: 1wriley@berkeley.edu 